\title{
Clinical aspects of hereditary hearing loss
}

Amit Kochhar, BS ${ }^{1}$, Michael S. Hildebrand, $P h D^{1}$, and Richard J. H. Smith, $M D^{1}$

\begin{abstract}
Hearing loss is an etiologically diverse condition with many disease-related complications and major clinical, social, and quality of life implications. As the rate of acquired hearing loss secondary to environmental causes decreases and improvements in the diagnosis of abnormalities occur, the significance of genetic factors that lead to deafness increases. Advancements in molecular biology have led to improved detection and earlier intervention in patients with hearing loss. Subsequently, earlier implementation of educational services and cochlear implant technology in patients with profound hearing loss now results in superior communication skills and enhanced language development. The aim of this review is to provide a comprehensive framework underlying the causes of hearing impairment and to detail the clinical management for patients with hereditary hearing loss. Genet Med 2007:9(7):
\end{abstract}

393-408.

Key Words: hereditary hearing loss, deafness, genetics, mutation, newborn hearing screening, congenital hearing loss, acquired hearing loss, syndromic hearing loss, nonsyndromic hearing loss

\section{Table of Contents}

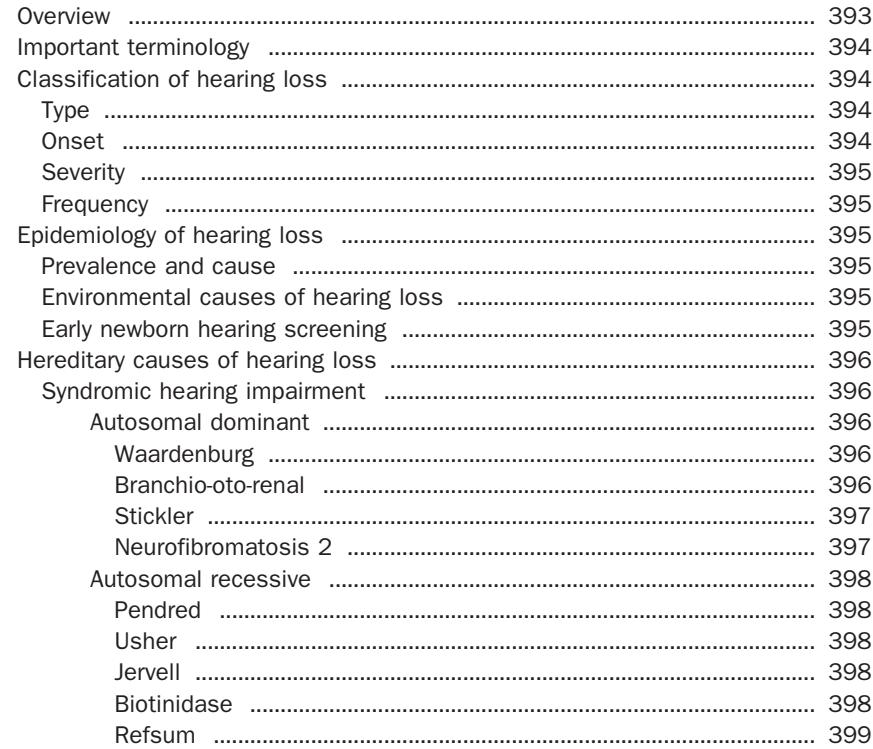

Hearing loss is the most common sensory disorder. It can be classified as conductive, sensorineural, or mixed (a combination of both); syndromic or nonsyndromic; and prelingual or postlingual. Estimates of the different types of genetic deafness exceed 400, and to date, 60 genes for syndromic and nonsyn-

From the ${ }^{1}$ Molecular Otolaryngology Research Laboratories, University of Iowa, Iowa City, Iowa

Disclosure: The authors declare no conflict of interest.

Richard J. H. Smith, MD, Molecular Otolaryngology Research Laboratories, Department of Otolaryngology-Head and Neck Surgery, 5270 CBRB, The University of Iowa, Iowa City, IA 52242.E-mail: richard-smith@uiowa.edu.

Submitted for publication February 28, 2007.

Accepted for publication April 13, 2007.

DOI: 10.1097/GIM.0b013e3180980bdo

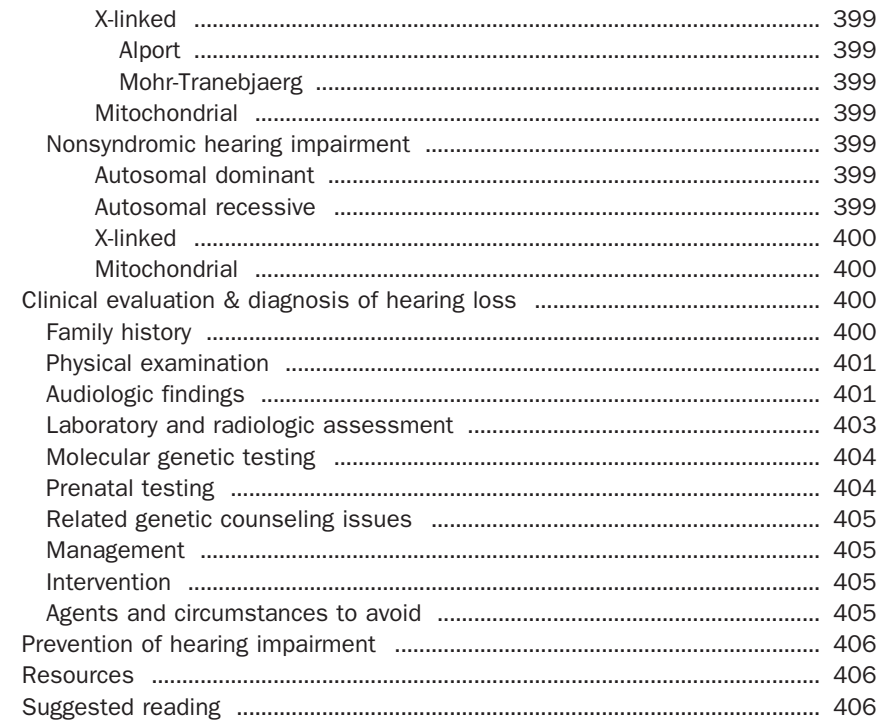

dromic hearing loss have been identified. ${ }^{1}$ The expression patterns of these genes in the inner ear can be visualized on the Hereditary Hearing Loss Homepage (http://webh01.ua.ac.be/ hhh/) (Fig. 1). ${ }^{2}$

In the investigation of hearing loss, genetic forms must be distinguished from acquired (nongenetic) causes. The diagnosis of hereditary hearing loss requires otologic, audiologic, and physical examinations; a family history; ancillary testing (e.g., computed tomography examination of the temporal bone); and molecular genetic analysis. Molecular genetic tests are available for many types of syndromic and nonsyndromic deafness, although often only on a research basis. Clinically, testing of GJB2 and GJB6 plays a prominent role in diagnosis and genetic counseling because mutations in these genes account for more than $50 \%$ of severe-to-profound autosomal 


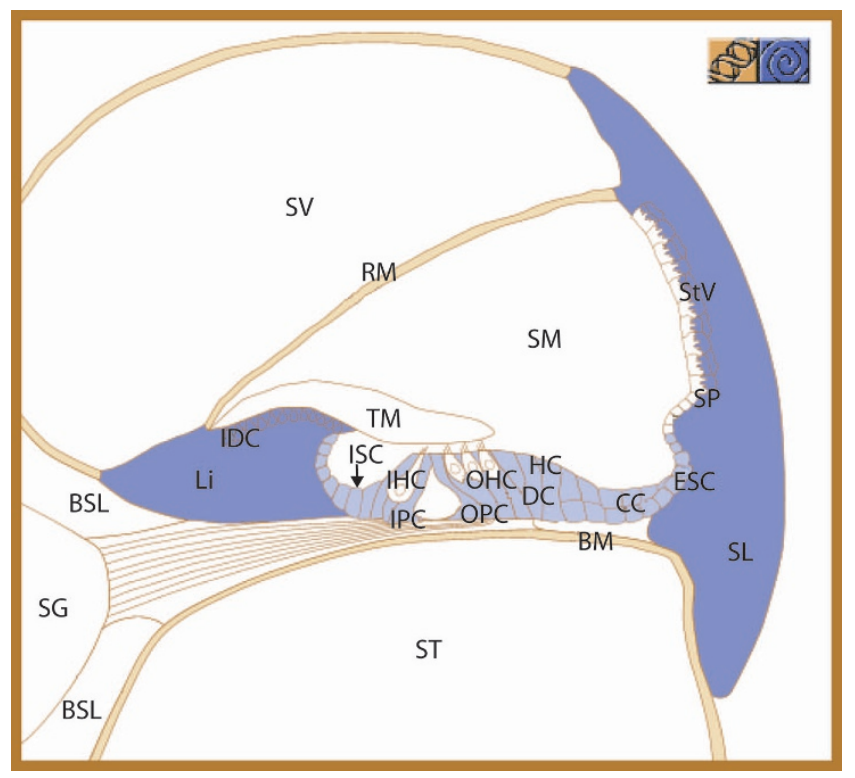

Fig. 1. Cochlear expression patterns of GJB2 BM, basilar membrane; BSL, bony spiral lamina; CC, Claudius cell; DC, Deiters cell; ESC, external sulcus cell; HC, Hensen cell; IDC, interdental cell; IHC, inner hair cell; IPC, inner pillar cell; ISC, inner sulcus cell; Li, limbus; OHC, outer hair cell; OPC, outer pillar cell; RM, Reissner membrane; SG, spiral ganglion; SL, spiral ligament; SM, scala media; SP, spiral prominence; ST, scala tympani; $\mathrm{StV}$, stria vascularis; SV, scala vestibuli; TM, tectorial membrane. With permission from Van Camp G, Smith RJH. Hereditary Hearing Loss Homepage, 2003. http:// webh01.ua.ac.be/hhh/. Accessed 24 January 2007.

recessive nonsyndromic deafness in many world populations. Table 1 indicates the other forms of deafness for which molecular genetic testing is currently available.

A genetic hearing loss may be inherited in an autosomal dominant, autosomal recessive, or X-linked Mendelian manner, or through the maternal lineage by mitochondrial inheritance. Genetic counseling and risk assessment are dependent on the accurate determination of the specific genetic diagnosis. In the absence of a specific diagnosis, empiric recurrence risk figures, coupled with GJB2 and GJB6 molecular genetic testing results, may be used for genetic counseling.

\section{IMPORTANT TERMINOLOGY}

"Hearing impairment" and "hearing loss" are often used interchangeably by health care professionals when referring to hearing below threshold levels for normal hearing determined by audiometry.

Deaf (small "d") is a colloquial term that implies hearing thresholds in the severe-to-profound range by audiometry.

Deaf culture (always a capital “D”) refers to members of the Deaf community in the United States who are deaf and use American Sign Language. As in other cultures, the Deaf are characterized by unique social and societal attributes. They do NOT consider themselves to be hearing "impaired," nor do they feel that they have a hearing "loss." Rather, they consider themselves deaf. Their deafness is not considered to be a pathology or disease to be treated or cured.

Hard of hearing is a term that is more functional than audiologic. It is used by the Deaf to signify that a person has some
Table 1

Molecular genetic testing available for clinical diagnosis of hereditary deafness

\begin{tabular}{ll}
\hline Syndromic deafness & Gene clinically tested \\
Branchio-Oto-Renal syndrome & EYA1 \\
$\begin{array}{c}\text { Mohr-Tranebjaerg syndrome (deafness- } \\
\text { dystonia-optic atrophy syndrome) }\end{array}$ & TIMM8A \\
Pendred syndrome & SLC26A4 \\
Usher syndrome type 1B & USH1B \\
Usher syndrome type 2A & USH2A \\
Usher syndrome type 3 & USH3A(one mutation) \\
Wolfram syndrome & WFS1 \\
& \\
Nonsyndromic deafness & Gene clinically tested \\
DFNA3 and DFNB1 & GJB2 and GJB6 \\
DFN3 & POU3F4 \\
DFNB4 & SLC26A4 \\
DFNA 6/14 & WFS1 \\
DFNA 8/12 & TECTA \\
DFNA9 & COCH \\
DFNB9 & OTOF \\
DFNB21 & TECTA \\
Mitochondrial hearing loss & \\
& Gene clinically tested \\
& MTTL1 \\
\hline
\end{tabular}

usable hearing: anything from mild to severe hearing loss. In the Deaf community, persons who are deaf do not use oral language, whereas those who are hard of hearing usually have some oral language.

\section{CLASSIFICATION OF HEARING LOSS}

Hearing loss is classified by type, onset, severity, and frequency.

\section{Type}

Conductive hearing loss results from abnormalities of the external ear and/or the ossicles of the middle ear. In contrast, sensorineural hearing loss results from the malfunction of inner ear structures such as the cochlea. Mixed hearing loss is a combination of both conductive and sensorineural hearing loss, and central auditory dysfunction results from damage or dysfunction at the level of the eighth cranial nerve, auditory brainstem, or cerebral cortex.

\section{Onset}

Prelingual hearing loss is present before speech develops. All congenital hearing loss is prelingual, but not all prelingual hearing loss is congenital. Postlingual hearing loss occurs after the development of normal speech. 


\section{Severity}

Hearing is measured in decibels $(\mathrm{dB})$. The threshold or $0 \mathrm{~dB}$ mark for each frequency refers to the level at which normal young adults perceive a tone burst $50 \%$ of the time. Hearing is considered normal if an individual's thresholds are within $15 \mathrm{~dB}$ of normal thresholds. Severity of hearing loss is graded as follows:

- Mild (26-40 dB)

- Moderate (41-55 dB)

- Moderately severe (56-70 dB)

- Severe (71-90 dB)

- Profound (90 dB)

To calculate the percent hearing impairment, $25 \mathrm{~dB}$ is subtracted from the pure tone average of $500 \mathrm{~Hz}, 1000 \mathrm{~Hz}, 2000$ $\mathrm{Hz}$, and $3000 \mathrm{~Hz}$. The result is multiplied by 1.5 to obtain an ear-specific level. Impairment is determined by weighting the better ear five times the poorer ear (Table 2). ${ }^{3}$

Note:

1. Because conversational speech is at approximately 50 to $60 \mathrm{~dB}$ hearing level (HL), calculating functional impairment on the basis of pure tone averages can be misleading. For example, a $45 \mathrm{~dB}$ hearing loss is functionally much more significant than $30 \%$ implies. ${ }^{4}$

2. A different rating scale is appropriate for young children, for whom even limited hearing loss can have a great impact on language development (Table 2). ${ }^{4}$

\section{Frequency}

The frequency of hearing loss is designated as follows:

- Low $(<500 \mathrm{~Hz})$

- Middle (501-2000 Hz)

- $\operatorname{High}(>2000 \mathrm{~Hz})$

\section{EPIDEMIOLOGY OF HEARING LOSS}

\section{Prevalence and cause}

Profound hearing loss is present in 1 of every 1000 to 2000 newborn infants. However, milder but still clinically significant degrees of unilateral or bilateral hearing loss occur in an additional one to two infants. ${ }^{5,6}$ More than 50\% of all prelingual deafness cases are hereditary in nature, with the remaining $40 \%$ to $50 \%$ of cases secondary to environmental factors such as infectious or iatrogenic causes (Fig. 2). ${ }^{7,8}$ The majority of genetic hearing loss diagnosed in infancy and early childhood is autosomal recessive in inheritance and nonsyndromic. Deaf-

Table 2

Percent hearing impairment

\begin{tabular}{lcc}
\hline Impairment $(\%)$ & Pure tone average $(\mathrm{dB})^{a}$ & Residual hearing (\%) \\
\hline $100 \%$ & $91 \mathrm{~dB}$ & $0 \%$ \\
$80 \%$ & $78 \mathrm{~dB}$ & $20 \%$ \\
$60 \%$ & $65 \mathrm{~dB}$ & $40 \%$ \\
$30 \%$ & $45 \mathrm{~dB}$ & $70 \%$ \\
\hline
\end{tabular}

${ }^{a}$ Pure tone average of $500 \mathrm{~Hz}, 1000 \mathrm{~Hz}, 2000 \mathrm{~Hz}$, and $3000 \mathrm{~Hz}$. ness at the DFNB1 locus is secondary to mutations in GJB2 and/or GJB6, which encode the proteins connexin 26 and connexin 30 , respectively, and accounts for $50 \%$ of autosomal recessive nonsyndromic hearing loss. The carrier rate for the general U.S. population of northern European descent for a recessive deafness-causing GJB2 mutation is approximately 1 in $33 .{ }^{9}$

Generally, the prevalence of hearing loss increases with age, reflecting the important impact of both genetics and the environment in its development. Indeed, interactions between environmental triggers and an individual's genotype can contribute to the development of hearing loss. For example, aminoglycosideinduced toxicity is potentiated on a genetic background that includes the mitochondrial DNA 1555 A-to-G mutation. ${ }^{10}$

\section{Environmental causes of hearing loss}

Acquired hearing loss in children commonly results from prenatal infections from the "TORCH" organisms (toxoplasmosis, rubella, cytomegalovirus, and herpes), or postnatally secondary to bacterial meningitis caused by Neisseria meningitides, Haemophilus influenzae, or Streptococcus pneumoniae, although meningitis-related hearing loss can be the sequelae of infections from Escherichia coli, Listeria monocytogenes, Streptococcus agalactiae, and Enterobacter cloacae (Fig. 2). Perhaps most noteworthy is hearing loss from asymptomatic congenital cytomegalovirus infection. This type of sensorineural hearing loss is highly variable, can fluctuate, and can be difficult to diagnose definitively, although a recently developed polymerase chain reaction-based assay can retrospectively diagnose patients by using preserved umbilical cord blood. ${ }^{11-14}$

Acquired hearing loss in adults is most often attributed to environmental factors, the most common being noise exposure. However, an individual's susceptibility to hearing loss most likely reflects an environmental-genetic interaction.

Age-related hearing loss (presbycusis) is acquired and characterized by diminished hearing sensitivity and speech comprehension in noisy environments, slowed central processing of acoustic information, and impaired localization of sound. Affected persons may have difficulty in conversation, music appreciation, orientation to alarms, and participation in social activities. ${ }^{15}$ The aging population in the Western world and the high prevalence of presbycusis combine to make age-related hearing loss a common social and health challenge. Ten percent of the Western population have a hearing loss severe enough to impair communication, and this rate increases to $40 \%$ in individuals aged more than 65 years.

\section{Early newborn hearing screening}

For the detection of congenital hearing loss, the U.S. federal government facilitated the creation of Early Hearing Detection and Intervention (EHDI) programs for early newborn hearing screening (http://www.infanthearing.org). EHDI programs aim to screen neonates for hearing loss immediately after birth or before hospital discharge. The programs include a follow-up arm to confirm hearing loss in neonates who do not pass their initial screening test so that intervention can be initiated to prevent delayed language acquisition. ${ }^{16}$ 


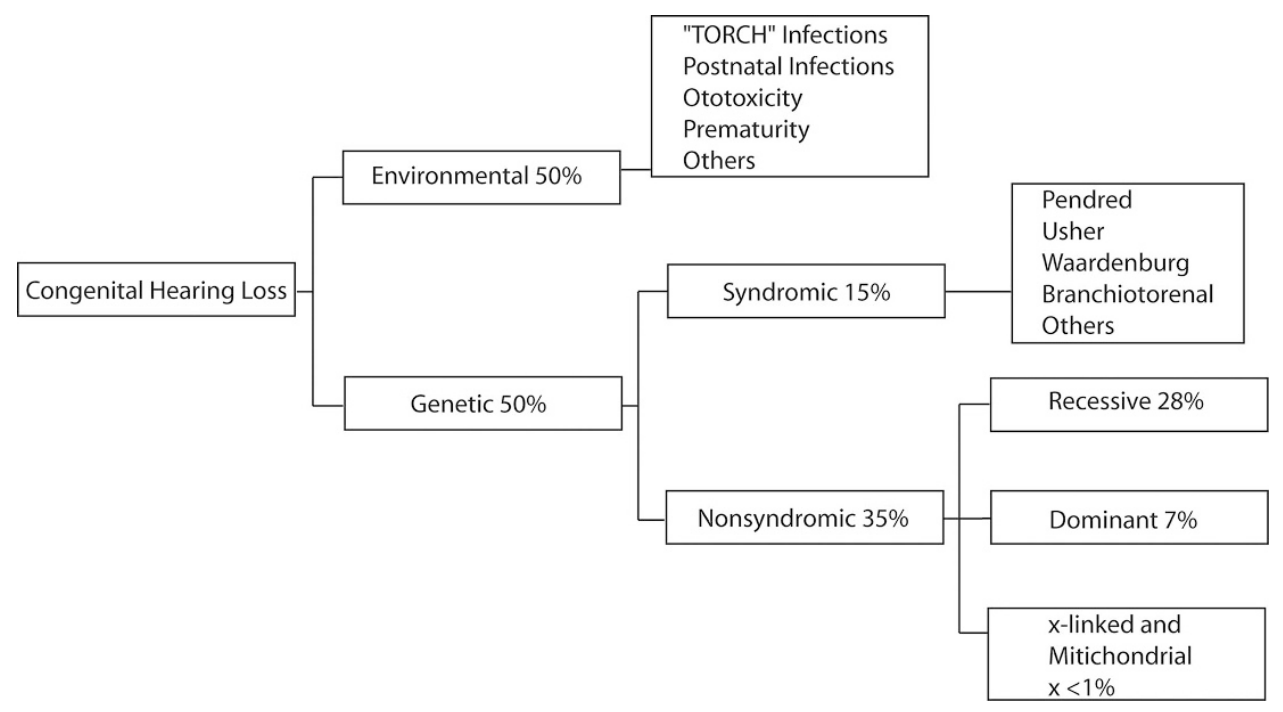

Fig. 2. Hereditary and environmental causes of congenital hearing loss.

EHDI program guidelines include three phases: screening, audiologic evaluation, and intervention (Fig. 3). In the first phase, newborns are screened with evoked otoacoustic emissions (EOAE) or auditory brainstem response (ABR) to detect permanent bilateral or unilateral sensory or conductive hearing loss averaging 30 to $40 \mathrm{~dB}$ HL or more in the frequency region important for speech recognition. In the second phase, all infants who do not pass the initial screen are evaluated with a series of diagnostic audiologic tests, preferably before the age of 3 months. In the third phase, early intervention services are implemented before the age of 6 months for all infants with confirmed hearing loss. ${ }^{16}$

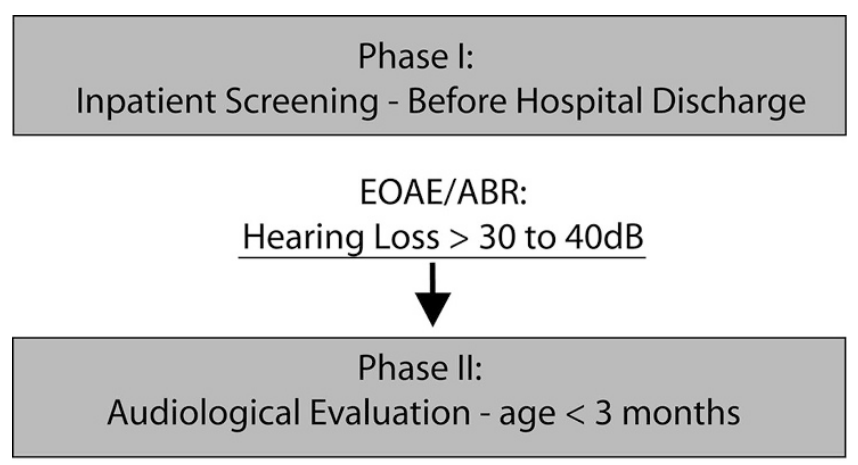

ABR, OAE or ASSR and Behavioral testing:

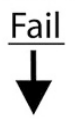

Phase III:

Intervention - age $<6$ months

Fig. 3. EHDI screening protocols. EOAE, evoked otoacoustic emissions; ABR, auditory brainstem response; $\mathrm{dB}$, decibel; OAE, otoacoustic emissions; ASSR, auditory steady-state response. Adapted with permission from www.infanthearing.org.

\section{HEREDITARY CAUSES OF HEARING LOSS}

\section{Syndromic hearing impairment}

Syndromic hearing impairment accounts for up to $30 \%$ of prelingual deafness, but its relative contribution to all deafness is smaller because of the impact of postlingual hearing loss. Some of the more prevalent forms of syndromic hearing loss are listed in Table 3.

\section{Autosomal dominant syndromic hearing impairment}

\section{Waardenburg syndrome}

Waardenburg syndrome (WS) is the most common type of autosomal dominant syndromic hearing loss. It consists of variable degrees of prelingual nonprogressive sensorineural hearing loss accompanied by pigmentary abnormalities of the skin, hair (white forelock), and eyes (heterochromia iridis). Because affected persons may dye their hair, the presence of a white forelock should be specifically sought in the history and physical examination. Four types are recognized-WS I, WS II, WS III, and WS IV-based on the presence or absence of other abnormalities. WS I and WS II share many features but have an important phenotypic difference; WS I is characterized by the presence of a lateral displacement of the inner canthus of the eye, which is known as dystopia canthorum, whereas in WS II this feature is absent. In WS III upper-limb abnormalities are present, and in WS IV, Hirschsprung disease is present. Mutations in PAX3 cause both WS I and WS III, and mutations in MITF and SNA12 are responsible for some cases of WS II. ${ }^{17-21}$ Mutations in $E D N R B, E D N 3$, and $S O X 10$ have been confirmed to cause WS IV $22-24$

\section{Branchio-oto-renal syndrome}

Branchio-Oto-Renal (BOR) syndrome is the second most common type of autosomal dominant syndromic hearing loss. The BOR phenotype includes conductive, sensorineural, or 
Table 3

The molecular genetics associated with syndromic hearing loss

\begin{tabular}{lcl}
\hline Syndrome & Chromosomal locus & Gene symb \\
\hline Autosomal dominant & & \\
Branchio-oto-renal (BOR) & & \\
BOR1 & $8 \mathrm{q} 13.3$ & EYA1 \\
BOR2 & $1 \mathrm{q} 31$ & Unknown \\
BOS3 & $14 \mathrm{q}$ & SIX1 \\
Waardenburg & & \\
WS1 & $2 \mathrm{q} 35$ & MITF \\
WS2 & $3 \mathrm{p} 14.1-\mathrm{p} 12.3$ & SNAI2 \\
WS3 & $2 \mathrm{q} 35$ & PAX3 \\
$\quad$ Klein-Waardenburg & & \\
syndrome) & & \\
WS4 (Shah-Waardenburg or & $13 \mathrm{q} 22$ & EDNRB \\
$\quad$ Waardenburg-Hirschsprung) & & \\
& $20 \mathrm{q} 13.2-\mathrm{q} 13.3$ & EDN3 \\
& $22 \mathrm{q} 13$ & SOX10
\end{tabular}

Stickler

STL1

STL2

STL3

STL4

Neurofibromatosis

NF2

Autosomal recessive

Pendred

Usher

USH1A

USHIB

USH1C

USH1D

USH1E

USH1F

USH1G

USH2A

USH2B

USH2C

USH3

Jervell and Lange-Nielsen

JLNS1

JLNS2

Biotinidase deficiency

Refsum

$\begin{array}{cc}12 \mathrm{q} 13.11-13.2 & \text { COL2A1 } \\ 6 \mathrm{p} 1.3 & \text { COL11A2 } \\ 1 \mathrm{p} 21 & \text { COL11A } \\ 6 \mathrm{q} 13 & \text { COL9A1 }\end{array}$

$22 \mathrm{q} 12$

NF2

7q21-34 SLC26A4/PDS

Unknown

MYO7A

USH1C

CDH23

Unknown

PCDH15

SANS

USH2A

Unknown

VLGR1

USH3A

3q21-q25 USH3A

$\begin{array}{cl}\text { 11p15.5 } & \text { KCNQ1 } \\ \text { 21q22.1-q22.2 } & \text { KCNE1 } \\ \text { 3p25 } & \text { BTD } \\ \text { 10pter-p11.2 } & \text { PHYH } \\ \text { 6q22-q24 } & \text { PEX7 }\end{array}$

(Continued)
Table 3

Continued

\begin{tabular}{lcc}
\hline Syndrome & Chromosomal locus & Gene symbol \\
\hline X-linked & & \\
Alport & $\mathrm{Xq} 22$ & COL4A5 \\
& $2 \mathrm{q} 36-2 \mathrm{q} 37$ & COL4A3 \\
& $2 \mathrm{q} 36-2 \mathrm{q} 37$ & COL4A4 \\
& $\mathrm{Xq} 22$ & TIMM8A \\
\hline
\end{tabular}

Adapted with permission from Van Camp G, Smith RJH. Hereditary Hearing Loss Homepage, 2003. http://webh01.ua.ac.be/hhh/. Accessed 24 January 2007.

mixed hearing loss; branchial cleft cysts or fistulae; malformations of the external ear; preauricular pits; and renal anomalies. ${ }^{25,26}$ Penetrance is high, and expressivity is extremely variable. ${ }^{27-29} \mathrm{In}$ approximately $40 \%$ of families segregating a BOR phenotype, mutations in the EYA1 gene have been identified. Mutations in SIX1 were recently discovered in a few BOR families without EYA1 mutations,$^{30}$ which is consistent with the known interaction of EYA1 and SIX1 proteins in transcriptional regulation and their involvement in the development of the mammalian ear and kidney. ${ }^{31-33}$ There are a large number of BOR cases that appear to be genetic but for which no mutation has been identified.

\section{Stickler syndrome}

Stickler syndrome is an autosomal dominant disorder of type 2 collagen resulting in sensorineural hearing loss, cleft palate, congenital myopia, and spondyloepiphyseal dysplasia that eventually leads to osteoarthritis. The syndrome is common, and three forms are recognized based on the precise molecular genetic defect involved. STL1 is caused by mutations in COL2A1, STL2 is caused by mutations in COL11A1, and STL3 occurs secondary to mutations in COL11A2..$^{34-37}$ STL1 and STL2 are characterized by severe myopia, which predisposes individuals to retinal detachment. Myopia is absent in STL3 because the COL11A2 gene is not expressed in the eye. Because of the substantial risk for retinal detachment, ophthalmologic assessment is mandatory in all persons diagnosed with STL1 and STL2.

\section{Neurofibromatosis 2}

Neurofibromatosis 2 (NF2) is associated with a rare, potentially treatable type of deafness. The hallmark of NF2 is hearing loss secondary to bilateral vestibular schwannomas. Impairment primarily begins in the third decade, concomitant with the growth of a vestibular schwannoma, and is generally unilateral and gradual but may be bilateral and sudden. ${ }^{38} \mathrm{~A}$ retrocochlear lesion can often be diagnosed by audiologic evaluation, although the definitive diagnosis requires magnetic resonance imaging with gadolinium contrast. Affected persons are at risk for a variety of other tumors including meningiomas, astrocytomas, ependymomas, and meningioangiomatosis. ${ }^{39}$ Mutations in NF2, which encodes the protein Merlin, are causative, and molecular genetic testing of NF2 is available for presymptomatic, at-risk family members to facilitate early diagnosis and treatment. 


\section{Autosomal recessive syndromic hearing impairment}

\section{Pendred syndrome}

Pendred syndrome is the most common form of syndromic hearing loss and is characterized by congenital severe-to-profound sensorineural hearing impairment, structural defects of the temporal bone and inner ear, and euthyroid goiter. Goiter is not present at birth and develops in early puberty $(40 \%)$ or adulthood (60\%). Delayed organification of iodine by the thyroid can be documented by a perchlorate discharge test. The hearing loss is associated with an abnormality of the bony labyrinth (Mondini dysplasia or dilated vestibular aqueduct) that can be diagnosed by computed tomography of the temporal bones (Fig. 4). ${ }^{40,41}$ Vestibular function is abnormal in the majority of affected persons.

Mutations in SLC26A4 (PDS) can be identified in approximately $50 \%$ of multiplex families with a Pendred syndrome phenotype, and genetic testing of this gene is appropriate for persons with Mondini dysplasia or an enlarged vestibular aqueduct and progressive hearing loss. Early studies reported that Pendred syndrome accounted for up to $7.5 \%$ of congenital deafness, but contemporary studies suggest that the prevalence of Pendred syndrome is lower. ${ }^{42,43}$ Mutations in SLC26A4 also cause autosomal recessive nonsyndromic hearing loss at the DFNB4 locus.

\section{Usher syndrome}

Usher syndrome is one of the most common types of autosomal recessive syndromic hearing loss and is characterized by dual sensory impairments. Affected individuals are born with sensorineural hearing loss and early in life develop retinitis pigmentosa, a progressive degeneration of the retina that leads to loss of night vision, restriction of visual fields, and blindness by adolescence. Usher syndrome affects more than $50 \%$ of the deaf-blind in the United States. ${ }^{44}$ It is of significance to note that the visual impairment from retinitis pigmentosa is usually not apparent in the first decade, thus making funduscopic examination before 10 years of age of limited utility. However, electroretinography can identify abnormalities in photoreceptor function in children as young as 2 to 4 years of age. During the second decade, night blindness and loss of peripheral vision become evident and inexorably progress.

Usher syndrome is both phenotypically and genotypically heterogeneous. Three types are recognized on the basis of the degree of hearing impairment and vestibular function. Usher syndrome type I is characterized by congenital severe-to-profound sensori- neural hearing loss and vestibular dysfunction. Affected persons find traditional sound amplification ineffective and usually communicate manually. Because of the vestibular deficit, developmental motor milestones for sitting and walking are generally achieved later than normal. Usher syndrome type II is characterized by congenital mild-to-severe sensorineural hearing loss and normal vestibular function. Hearing aids provide effective sound amplification for these persons, and their communication is usually oral. Usher syndrome type III is the rarest form and is characterized by progressive hearing loss and progressive deterioration of vestibular function. ${ }^{45}$

\section{Jervell and Lange-Nielsen syndrome}

Jervell and Lange-Nielsen syndrome is the third most common type of autosomal syndromic hearing loss. The syndrome consists of congenital sensorineural hearing loss and prolongation of the QT interval as detected by electrocardiography (the abnormal QTc [c = corrected] is $>440 \mathrm{~ms}$ ). Affected individuals have syncopal episodes and may have sudden death. Although a screening electrocardiogram is not highly sensitive, it may be suitable for screening deaf children. High-risk children (i.e., those with a family history that is positive for sudden death, sudden infant death syndrome, syncopal episodes, or long QT syndrome) should have a thorough cardiac evaluation. Mutations in two genes, KCNQ1 and $K C N E 1$, have been identified in affected persons. ${ }^{46,47}$

\section{Biotinidase deficiency}

Biotinidase deficiency is secondary to absence of the watersoluble B-complex vitamin biotin. Biotin covalently binds to four carboxylases that are essential for gluconeogenesis, fatty acid synthesis, and catabolism of several branched-chain amino acids. If biotinidase deficiency is not recognized and corrected by daily addition of biotin to the diet, affected persons develop neurologic features such as seizures, hypertonia, developmental delay, ataxia, and visual problems. Furthermore, in at least $75 \%$ of children who become symptomatic, sensorineural hearing loss develops and can be both profound and persistent even after treatment is initiated. ${ }^{48}$ Cutaneous features are also present and include a skin rash, alopecia, and conjunctivitis. With treatment that consists of biotin replacement, the neurologic and cutaneous manifestations resolve; however, the hearing loss and optic atrophy are usually irreversible. Therefore, if a child presents with episodic or progressive ataxia and progressive sensorineural deafness,
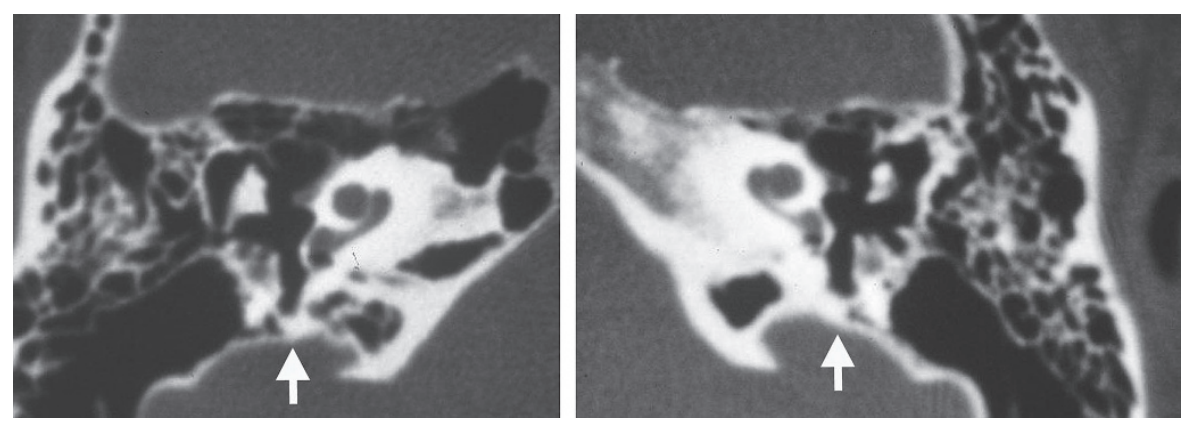

Fig. 4. Dilated vestibular aqueduct (arrows) as shown by computed tomography scan of the temporal bone in a person with Pendred syndrome. 
with or without neurologic or cutaneous symptoms, biotinidase deficiency should be considered. To prevent metabolic coma, diet and treatment should be initiated as soon as possible. ${ }^{48,49}$

\section{Refsum disease}

Refsum disease is a postlingual severe progressive sensorineural hearing loss associated with retinitis pigmentosa, peripheral neuropathy, cerebellar ataxia, and elevated protein levels in the cerebrospinal fluid without an increase in the number of cells. ${ }^{50}$ It is caused by defective phytanic acid metabolism, and as such, the diagnosis is established by determining the serum concentration of phytanic acid. Two genes, $P H Y H$ and PEX7, have been implicated in the majority of Refsum cases, although a small number of patients exist in whom mutations have not been found. $.^{51} \mathrm{Al}-$ though Refsum disease is rare, it is important that it be considered in the evaluation of a deaf person because it can be easily treated with dietary modification and plasmapheresis.

\section{X-linked syndromic hearing impairment}

\section{Alport syndrome}

Alport syndrome is characterized by progressive postlingual sensorineural hearing loss of varying severity, progressive glomerulonephritis leading to end-stage renal disease, and variable ophthalmologic findings such as anterior lenticonus. Hearing loss usually does not manifest before the first decade of life, and the progressive myopia secondary to anterior lenticonus is considered by some authors to be sufficient to diagnose Alport syndrome..$^{52}$ Autosomal dominant, autosomal recessive, and X-linked inheritance are described. X-linked forms account for approximately $85 \%$ of cases and are attributable to mutations in COL4A5, a member of the type IV collagen gene family..$^{53}$ Autosomal recessive inheritance accounts for the majority of the remaining $15 \%$ of cases, with only a few autosomal dominant cases documented.

\section{Mohr-Tranebjaerg syndrome (deafness-dystonia-optic atrophy syndrome)}

Mohr-Tranebjaerg syndrome was first described in a large Norwegian family with apparent progressive postlingual nonsyndromic hearing impairment and classified as DFN1. ${ }^{54}$ Reevaluation of this family, however, revealed additional findings, including visual disability, dystonia, fractures, and mental retardation, indicating that this form of hearing impairment is syndromic rather than nonsyndromic. ${ }^{55}$ The gene for this syndrome, TIMM8A, is involved in the translocation of proteins from the cytosol across the inner mitochondrial membrane (TIM system) and into the mitochondrial matrix. ${ }^{56,57}$

\section{Mitochonrial syndromic hearing impairment}

Mitochondrial DNA mutations have been implicated in a variety of diseases ranging from rare neuromuscular syndromes, such as Kearns-Sayre syndrome; mitochondrial encephalopathy, lactic acidosis, and stroke-like episodes; myoclonic epilepsy and ragged red fibers; and neuropathy, ataxia, and retinitis pigmentosa syndrome; to common conditions, such as diabetes mellitus, Parkinson disease, and Alzheimer disease. One mutation, the $3243 \mathrm{~A}-\mathrm{to}-\mathrm{G}$ transition in the gene MTTL1, has been found in $2 \%$ to $6 \%$ of individuals with diabetes mellitus in Japan..$^{58}$ Sixty-one percent of patients with diabetes mellitus carrying this mutation also have hearing loss. ${ }^{58-60}$ The hearing loss is sensorineural and develops only after the onset of the diabetes mellitus. The same mutation is associated with mitochondrial encephalopathy, lactic acidosis, and stroke-like episodes, raising questions of penetrance and tissue specificity, issues further confounded by heteroplasmy associated with mitochondrial conditions.

\section{Nonsyndromic hearing impairment}

More than 70\% of hereditary hearing loss is nonsyndromic. ${ }^{61,62}$ Disorders discussed in this section are organized by mode of inheritance. The different gene loci for nonsyndromic deafness are designated DFN (for DeaFNess). Loci for genes inherited in an autosomal dominant manner are referred to as DFNA, loci for genes inherited in an autosomal recessive manner are referred to as DFNB, and loci for genes inherited in an X-linked manner are referred to as DFN. The number following these designations reflects the order of gene mapping and/or discovery.

It is important to realize that several recessive and dominant loci have been mapped to the same chromosomal region, and in many of these cases, allelic variants of a single gene have been found. Examples include DFNB2 and DFNA11, both of which map to 11q13.5 and are caused by mutations in MYO7A, the gene that also causes Usher syndrome 1B, and DFNB21 and DFNA8/12, both of which are caused by mutations in TECTA.

\section{Autosomal dominant nonsyndromic hearing impairment}

The characteristic phenotype of a person with autosomal dominant nonsyndromic hearing impairment is a progressive postlingual hearing loss that begins in the second to third decades of life. The condition is extremely heterogeneous, with multiple genes implicated in its pathogenesis. Audioprofiles may be distinct and therefore useful in predicting candidate genes for mutation screening. For example, mutations in WFS1 are found in 75\% of families segregating autosomal dominant nonsyndromic hearing impairment that initially affects the low frequencies while sparing the high frequencies (Fig. 5). Characteristic phenotypes are noted in Table 4, which also lists the genes known to be associated with autosomal dominant nonsyndromic hearing impairment.

\section{Autosomal recessive nonsyndromic hearing impairment}

In many world populations, mutations in GJB2 account for $50 \%$ of persons with autosomal recessive nonsyndromic hearing loss. ${ }^{63-65}$ The remaining $50 \%$ of cases are attributed to mutations in numerous other genes, many of which have been found to cause deafness in only one or two families. ${ }^{66,67}$ Extensive genotype-phenotype studies have shown that it is possible to predict the hearing loss associated with GJB2 mutations based on the specific genotype (Fig. 6). ${ }^{68}$ The largest study to date involved a crosssectional analysis of GJB2 genotype and audiometric data from 


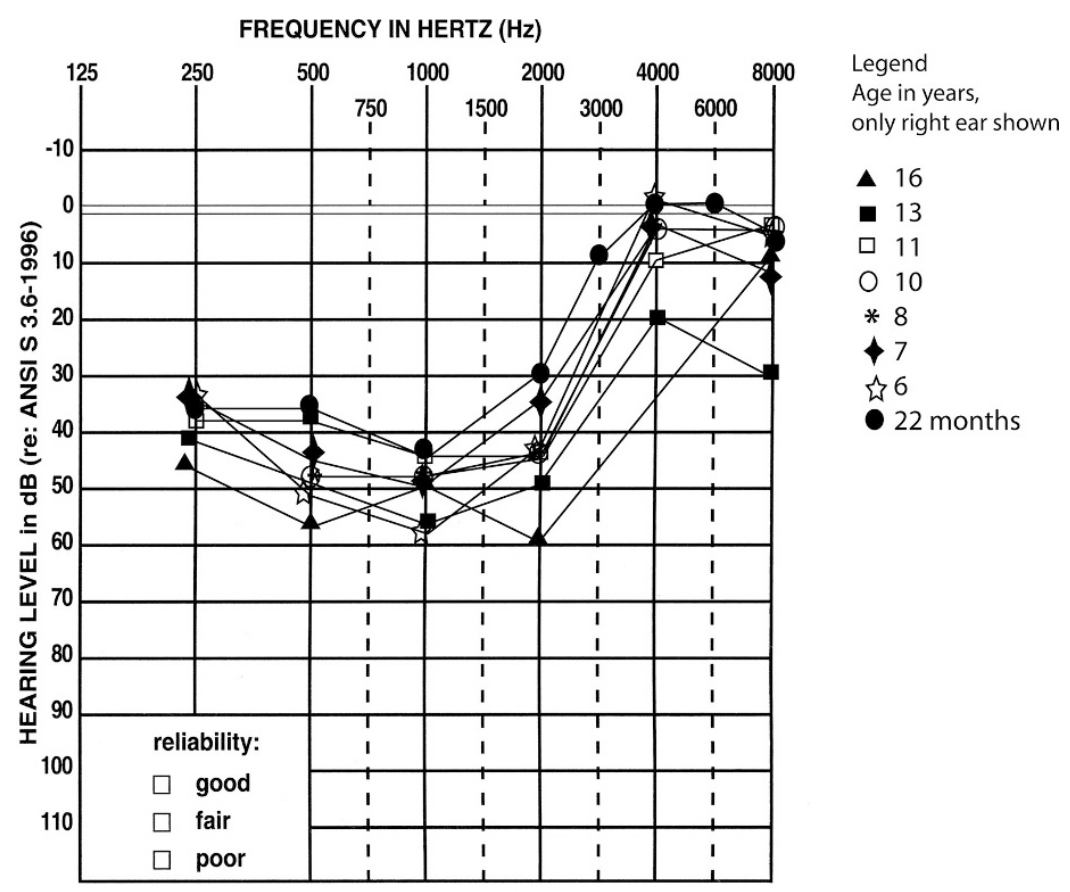

Fig. 5. Audioprofile for a family with DFNA6/14/38 hearing loss. An audioprofile is a recording of several audiograms on a single graph. These audiograms may be from one individual at different times, but frequently they are from different members of the same family segregating deafness usually in an autosomal dominant fashion. This represents a high-frequency hearing loss. dB, decibel; ANSI, American National Standards Institute. Adapted from Smith RJH, Van Camp G. Deafness and hereditary hearing loss review. (Last revised January 30, 2007.) Available at: http://www.genetests.org. Reprinted with permission from the University of Washington, Seattle.

1531 persons from 16 different countries with autosomal recessive, mild-to-profound, nonsyndromic deafness. ${ }^{68}$

The clinical manifestations, molecular genetics, and phenotypes of genes known to cause autosomal recessive nonsyndromic hearing impairment are summarized in Table 5.

\section{X-linked nonsyndromic hearing impairment}

DFN3 (mapped to Xq21.1) is characterized by a mixed conductive-sensorineural hearing loss, the conductive component of which is caused by stapedial fixation. In contrast with other types of conductive hearing loss, surgical correction is not accepted because an abnormal communication between the cerebrospinal fluid and perilymph results in leakage known as "perilymphatic gusher." Thus, a complete loss of hearing occurs when the oval window is fenestrated or removed. Radiology with computed tomography is helpful and demonstrates a dilation of the internal auditory meatus with an abnormal communication between the subarachnoid space and the cochlear endolymph. The causative gene for DFN3 is POU3F4. ${ }^{69}$

Additional X-linked nonsyndromic hearing loss phenotypes include profound prelingual hearing loss characteristic of both DFN2 and DFN4. DFN6 is characterized by a bilateral highfrequency impairment beginning at 5 to 7 years of age and progressing, by adulthood, to severe-to-profound hearing impairment, covering all frequencies.

Clinical manifestations and molecular genetics of genes known to cause $\mathrm{X}$-linked nonsyndromic hearing impairment are summarized in Table 6.

\section{Mitochondrial nonsyndromic hearing impairment}

Some mitochondrial DNA mutations cause nonsyndromic hearing loss (Table 7). In two families, a homoplasmic mutation at nt1555 (A-to-G) in the mitochondrial MTRNR1 gene has been reported. This mutation is also present in persons with aminoglycoside-induced ototoxic hearing loss. Two other families with maternally inherited nonsyndromic hearing loss have been identified with heteroplasmy for an A-to-G transition at nt7445 of the MTTS1 gene. The penetrance of the hearing impairment caused by these mitochondrial mutations is low, suggesting that unidentified genetic or environmental factors play an important role in the progression of the hearing impairment. ${ }^{70}$

\section{CLINICAL EVALUATION AND DIAGNOSIS OF HEARING LOSS}

Correctly diagnosing the specific cause of hearing loss can provide important prognostic information and is essential for accurate genetic counseling. The following clinical assessments are recommended.

\section{Family history}

A three-generation family history with attention to other relatives with hearing loss and associated findings should be obtained. Documentation of relevant findings in relatives can be accomplished through direct examination of those individuals or through review of their medical records, including au- 
Table 4

Clinical manifestations, molecular genetics, and phenotypes associated with autosomal dominant nonsyndromic hearing impairment

\begin{tabular}{|c|c|c|c|}
\hline Locus name & Chromosomal locus & Gene symbol & Phenotype \\
\hline DFNA1 & $5 q 31$ & DIAPH1 & Postlingual low-frequency hearing loss (first decade) \\
\hline \multirow[t]{2}{*}{ DFNA2 } & $1 \mathrm{p} 35.1$ & GJB3 & Postlingual high-frequency hearing loss (second) \\
\hline & $1 \mathrm{p} 34$ & KCNQ4 & \\
\hline \multirow[t]{2}{*}{ DFNA3 $^{a}$} & $13 q 11-q 12$ & GJB2 & Prelingual high-frequency hearing loss \\
\hline & $13 \mathrm{q} 12$ & GJB6 & \\
\hline DFNA4 & $19 \mathrm{q} 13$ & MYH14 & Postlingual hearing loss with flat/gently downsloping audioprofile \\
\hline DFNA5 & $7 \mathrm{p} 15$ & DFNA5 & Postlingual high-frequency hearing loss (first) \\
\hline DFNA6/14/38 ${ }^{b}$ & $4 \mathrm{p} 16.1$ & WFS1 & Prelingual low-frequency hearing loss \\
\hline DFNA8 $/ 12^{a}$ & $11 \mathrm{q} 22-\mathrm{q} 24$ & TECTA & Prelingual mid-frequency hearing loss \\
\hline DFNA9 & $14 q 12-q 13$ & $\mathrm{COCH}$ & Postlingual high-frequency hearing loss (second) \\
\hline DFNA10 & $6 \mathrm{q} 23$ & EYA4 & $\begin{array}{l}\text { Postlingual hearing loss with flat/gently downsloping audioprofile } \\
\text { (third/fourth) }\end{array}$ \\
\hline DFNA11 & $11 \mathrm{q} 13.5$ & MYO7A & Postlingual hearing loss (first) \\
\hline DFNA13 & $6 \mathrm{p} 21.3$ & COL11A2 & Postlingual mid-frequency hearing loss (second) \\
\hline DFNA15 & $5 q 31$ & POU4F3 & Postlingual high-frequency hearing loss \\
\hline DFNA17 & 22q11.2 & МYH9 & Postlingual high-frequency hearing loss \\
\hline DFNA20/26 & $17 \mathrm{q} 25$ & ACTG1 & Postlingual high-frequency hearing loss \\
\hline DFNA22 & $6 \mathrm{q} 13$ & MYO6 & Postlingual high-frequency hearing loss \\
\hline DFNA28 & $8 \mathrm{q} 22$ & TFCP2L3 & Postlingual hearing loss with flat/gently downsloping audioprofile \\
\hline DFNA36 & $9 q 13-q 21$ & $T M C 1$ & \\
\hline DFNA39 & $4 \mathrm{q} 21.3$ & $D S P P$ & Postlingual high-frequency hearing loss \\
\hline DFNA48 & $12 \mathrm{q} 13-\mathrm{q} 14$ & MYO1A & Postlingual hearing loss \\
\hline
\end{tabular}

${ }^{a}$ Most autosomal dominant disorders cause postlingual hearing impairment. Some exceptions are DFNA3, DFNA8, and DFNA12.

${ }^{b}$ DFNA6/1438 is noteworthy because the hearing loss primarily affects the low frequencies.

Adapted with permission from Van Camp G, Smith RJH. Hereditary Hearing Loss Homepage, 2003. http://webh01.ua.ac.be/hhh/. Accessed 24 January 2007.

diograms, otologic examinations, and DNA-based testing with appropriate consent.

\section{Physical examination}

All persons with hearing loss of unknown cause should be evaluated for features associated with syndromic deafness. Important features include branchial cleft pits, cysts or fistulae, preauricular pits, telecanthus, heterochromia iridis, white forelock, pigmentary anomalies, high myopia, pigmentary retinopathy, goiter, and craniofacial and skeletal anomalies. Neurologic examination of vestibular function with an ophthalmologic examination should be completed. The variable expressivity associated with syndromic deafness requires careful physical examination of the proband and other family members to make a correct diagnosis.

\section{Audiologic findings}

Establishing the diagnosis of a child or adult with presumed hereditary hearing loss can be difficult. One must both objectively assess auditory function and subjectively determine how a person processes auditory information, that is, hears. Physiologic tests, such as the ABR and the EOAE, are important objective determinants of the functional status of the auditory system and can be performed at any age. Audiometry refers to subjective testing that consists of both behavioral testing and pure tone measurement of air and bone sound conduction.

ABR uses sound stimuli in the form of clicks to evoke electrophysiologic responses that originate in the eighth cranial nerve and auditory brainstem. Surface electrodes record these responses and create a "wave $\mathrm{V}$ detection threshold." The ABR detection threshold correlates best with hearing sensitivity in the 1500 - to $4000-\mathrm{Hz}$ region in neurologically normal individuals. However, ABR does not reliably assess responses at low frequency $(<1500 \mathrm{~Hz})$.

Auditory steady-state response testing is an electrophysiologic measure of hearing acuity. Skin electrodes measure if the auditory response is phase locking to alterations in a continuous tonal stimulus. The continuous signal denotes that the average sound pressure level delivered is higher than that achieved with ABR, which uses repetitive click stimuli. This difference allows for auditory steady-state response testing to 


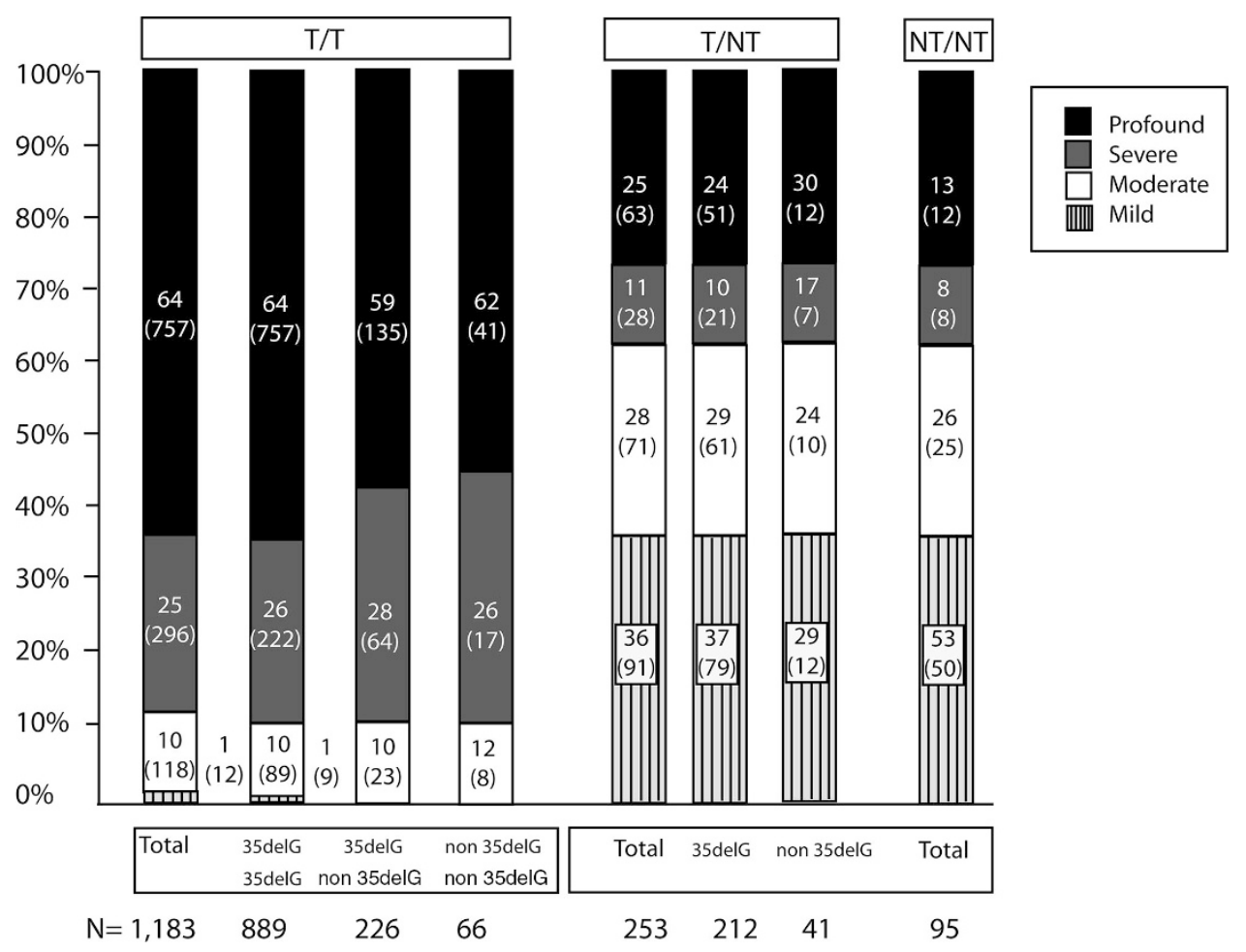

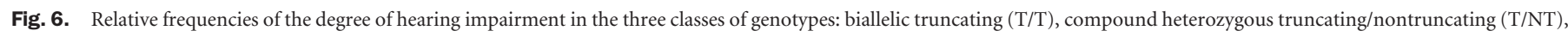

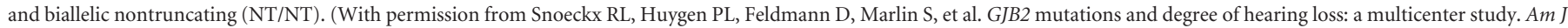
Hum Genet 2005;77:945-957.)

$\mathrm{T} / \mathrm{T}$ mutations comprised $35 \%$ of all genotypes, and the degree of hearing impairment in these persons was profound in $59 \%$ to $64 \%$ of persons, severe in $25 \%$ to $28 \%$ of persons,

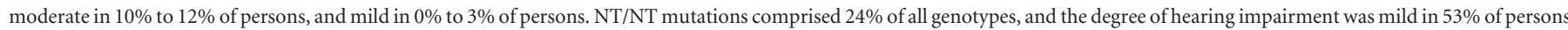

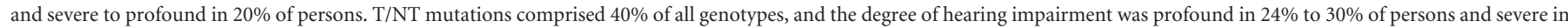
$10 \%$ to $17 \%$ of persons.

provide a measure of hearing sensitivity in children who demonstrate no response to ABR testing.

EOAEs are sounds that originate within the cochlea and are measured in the external auditory canal using a probe with a microphone and transducer. EOAEs principally reflect the activity of the outer hair cells of the cochlea across a broad frequency range. EOAEs are only present in ears with hearing sensitivity better than 40 to $50 \mathrm{~dB}$ HL.

Immittance testing includes tympanometry, testing of acoustic reflex thresholds, and acoustic reflex decay. Immittance audiometry evaluates the peripheral auditory system, including middle ear pressure, tympanic membrane mobility, eustachian tube function, and mobility of the middle ear ossicles.

Behavioral testing includes behavioral observation audiometry and visual reinforcement audiometry. Behavioral observation audiometry is used in infants from birth to age 6 months and is highly dependent on the skill of the tester. Thus, behavioral observation audiometry is subject to error. Visual reinforcement audiometry is used in children from age 6 months to 2.5 years and may provide a reliable, complete audiogram. However, the skill of the tester is also essential to visual reinforcement audiometry, as is the child's maturational age.

Pure-tone audiometry (air and bone conduction) seeks to determine the lowest intensity at which an individual "hears" a pure tone as a function of frequency or pitch. Octave frequencies from 250 (close to middle C) to $8000 \mathrm{~Hz}$ are tested using earphones. Intensity or loudness is measured in decibels, defined as the ratio between two sound pressures. The average threshold for a normal hearing adult is between 0 and $20 \mathrm{~dB} H \mathrm{HL}$, whereas sound at $120 \mathrm{~dB}$ HL is so loud that it can cause pain. Speech reception thresholds and speech discrimination are both assessed during pure-tone audiometric testing.

Air conduction audiometry presents sounds through earphones with thresholds dependent on the condition of the external ear canal, middle, and inner ear. Bone conduction audiometry presents sounds through a vibrator placed on the mastoid bone or forehead, bypassing the external and middle ears. Thus, thresholds are dependent on the condition of the inner ear. Conditioned play audiometry is used to test children from age 2.5 to 5 years. If a child is cooperative, a complete frequency-specific audiogram for each ear can be obtained. In conventional audiometry, the individual indicates when the sound is heard and is used to test individuals age 5 years and older.

An audioprofile refers to the recording of several audiograms on a single graph (Fig. 5). The audiograms may be from one individual at different times, but more frequently they are from different members of the same family that segregate for 
Table 5

Clinical manifestations, molecular genetics, and phenotypes associated with autosomal recessive nonsyndromic hearing impairment

\begin{tabular}{|c|c|c|c|}
\hline Locus name & Chromosomal locus & Gene symbol & Phenotype \\
\hline \multirow[t]{2}{*}{ DFNB1 } & $13 q 11-112$ & GJB2 & Prelingual ${ }^{a}$ hearing loss that remains relatively stable \\
\hline & $13 \mathrm{q} 12$ & GJB6 & \\
\hline DFNB2 & $11 \mathrm{q} 13.5$ & MYO7A & Prelingual or postlingual hearing loss of unspecified type \\
\hline DFNB3 & $17 \mathrm{p} 11.2$ & MYO15 & Prelingual hearing loss that remains relatively stable \\
\hline DFNB4 & $7 \mathrm{q} 31$ & SLC26A4 & $\begin{array}{l}\text { Prelingual or postlingual hearing loss that may be stable or progressive. } \\
\text { May also be associated with dilation of the vestibular aqueduct. }\end{array}$ \\
\hline DFNB6 & $3 \mathrm{p} 21$ & TMIE & Prelingual hearing loss that remains relatively stable \\
\hline DFNB7/11 & $9 q 13-q 21$ & $T M C 1$ & Prelingual hearing loss that remains relatively stable \\
\hline DFNB8/10 & $21 \mathrm{q} 22.3$ & TMPRSS3 & $\begin{array}{l}\text { Postlingual (DFNB8) })^{b} \text { or prelingual (DFNB10) hearing loss that may be } \\
\text { progressive or stable }\end{array}$ \\
\hline DFNB9 & $2 \mathrm{p} 22-\mathrm{p} 23$ & OTOF & Prelingual hearing loss that remains relatively stable \\
\hline DFNB12 & $10 \mathrm{q} 21-\mathrm{q} 22$ & $\mathrm{CDH} 23$ & Prelingual hearing loss that remains relatively stable \\
\hline DFNB16 & $15 q 15$ & STRC & $\begin{array}{l}\text { Prelingual hearing loss that remains relatively stable and is more } \\
\text { pronounced in the higher frequencies }\end{array}$ \\
\hline DFNB18 & $11 \mathrm{p} 15.1$ & USH1C & Prelingual hearing loss that remains relatively stable \\
\hline DFNB21 & $11 \mathrm{q} 22-\mathrm{q} 24$ & TECTA & Prelingual severe-to-profound isolated SNHL \\
\hline DFNB22 & $16 \mathrm{p} 12.2$ & OTOA & Prelingual moderate-to-severe SNHL \\
\hline DFNB23 & $10 \mathrm{q} 21.1$ & PCDH15 & Prelingual severe-to-profound SNHL \\
\hline DFNB28 & $22 \mathrm{q} 13.1$ & TRIOBP & Prelingual severe-to-profound SNHL \\
\hline DFNB29 & $21 \mathrm{q} 22.3$ & CLDN14 & Prelingual profound SNHL \\
\hline DFNB30 & $10 \mathrm{p} 11.1$ & MYO3A & $\begin{array}{l}\text { Progressive hearing loss that first affects the high frequencies and } \\
\text { begins in the second decade is severe in high and middle frequencies } \\
\text { and moderate at low frequencies by age } 50 \mathrm{y}\end{array}$ \\
\hline DFNB31 & $9 q 32-q 34$ & DFN31 & Prelingual profound SNHL \\
\hline DFNB36 & $1 \mathrm{p} 36.31$ & $E S P N$ & Prelingual hearing loss of unspecified or unknown type \\
\hline DFNB37 & $6 \mathrm{q} 13$ & MYO6 & Prelingual hearing loss of unspecified or unknown type \\
\hline DFNB67 & $6 \mathrm{p} 21.1-\mathrm{p} 22.3$ & TMHS & Prelingual profound SNHL \\
\hline
\end{tabular}

SNHL, sensorineural hearing loss.

${ }^{a}$ Prelingual deafness also includes congenital deafness.

${ }^{b}$ The onset of DFNB8 hearing loss is postlingual (10-12 years of age), whereas the onset of DFNB10 hearing loss is prelingual (congenital). This phenotypic difference reflects a genotypic difference: the DFNB8-causing mutation is a splice site mutation, suggesting that inefficient splicing is associated with a reduced amount of normal protein, which is sufficient to prevent prelingual deafness but not sufficient to prevent eventual hearing loss.

Adapted with permission from Van Camp G, Smith RJH. Hereditary Hearing Loss Homepage, 2003. http://webh01.ua.ac.be/hhh/. Accessed 24 January 2007.

deafness in an autosomal dominant trend. Plotting several audiograms with respective ages on the same graph allows for an age-related progression of hearing loss to be appreciated within a particular family. The composite picture is often characteristic of a specific genetic cause of autosomal dominant nonsyndromic hearing loss. One of the more characteristic audioprofiles is associated with DFNA6/14/38 hearing loss caused by mutations in WFS1 (Fig. 5).

In older children or adults, a standard audiogram can be obtained. The presence or absence of hearing loss in other family members should be documented by formal audiometric testing. Individuals with progressive hearing loss should be evaluated for Alport syndrome, Pendred syndrome, and Stickler syndrome. Testing should also include temporal bone computed tomography.
Sudden or rapidly progressive hearing loss can present with temporal bone anomalies or be secondary to a neoplasm. Furthermore, immunologic diseases, trauma, infections such as syphilis and Lyme disease, and metabolic, neurologic, or circulatory disturbances may also lead to sudden hearing loss.

\section{Laboratory and radiologic assessment}

A thorough history and physical examination will support specific laboratory evaluations that are directed toward the suspected diagnosis. This includes an immunoglobulin-M antibody assay in the first few years of life to assess for intrauterine infections such as cytomegalovirus and hemoglobinopathy testing that may be associated with sensorineural hearing loss. Urinalysis and renal function tests may also be performed if Alport syndrome is suspected, and thyroid function tests 
Table 6

Clinical manifestations, molecular genetics, and phenotypes associated with X-linked nonsyndromic hearing impairment

\begin{tabular}{|c|c|c|c|}
\hline Locus name & Chromosomal locus & Gene symbol & Phenotype \\
\hline DFN2 & $\mathrm{Xq} 22$ & - & Prelingual profound SNHL in all frequencies \\
\hline DFN3 & $\mathrm{Xq} 21.1$ & POU3F4 & $\begin{array}{l}\text { Mixed variable prelingual hearing loss that } \\
\text { progresses to profound in all frequencies }\end{array}$ \\
\hline DFN4 & $\mathrm{Xp} 21$ & - & $\begin{array}{l}\text { Stable prelingual profound SNHL in all } \\
\text { frequencies }\end{array}$ \\
\hline DFN5 & Withdrawn & - & - \\
\hline DFN6 & Xp22 & - & $\begin{array}{l}\text { Progressive severe-to-profound postlingual (first } \\
\text { decade) SNHL that begins with high-frequency } \\
\text { hearing loss that evolves to include all } \\
\text { frequencies by adulthood. }\end{array}$ \\
\hline DFN7 & Withdrawn & - & - \\
\hline DFN8 & Reserved & - & - \\
\hline
\end{tabular}

SNHL, sensorineural hearing loss.

Adapted with permission from Van Camp G, Smith RJH. Hereditary Hearing Loss Homepage, 2003. http://webh01.ua.ac.be/hhh/. Accessed 24 January 2007.

Table 7

Clinical manifestations, molecular genetics, and phenotypes associated with mitochondrial nonsyndromic hearing impairment

\begin{tabular}{lcc}
\hline Gene symbol & Mutation & Phenotype \\
\hline MTRNR1 & 961 different mutations inc.1494 C $>$ Tc.1555 A $>\mathrm{G}$ & $\begin{array}{c}\text { Commonly secondary to aminoglycoside use with variably } \\
\text { severity and highly variable penetrance } \\
\text { MTTS1 }\end{array}$ \\
c.7445 A $>$ Gc.7472 ins Cc.7510 T $>$ Cc.7511 T & Variably severe hearing loss with highly variable penetrance
\end{tabular}

Adapted with permission from Van Camp G, Smith RJH. Hereditary Hearing Loss Homepage, 2003. http://webh01.ua.ac.be/hhh/. Accessed 24 January 2007.

should be ordered for patients with presumed Pendred syndrome. ${ }^{71}$

Computed tomography is the best radiologic test for the evaluation of hearing impairment for anatomic abnormalities such as Mondini malformation or dilated vestibular aqueduct.72,73 $\mathrm{Pa}-$ tients with hearing loss should also receive renal ultrasound to assess for abnormalities that may be associated with syndromic hearing loss such as BOR.

\section{Molecular genetic testing}

GJB2 and GJB6 molecular testing should be considered in the evaluation of individuals with congenital nonsyndromic sensorineural hearing loss and in families with nonsyndromic hearing loss in which two generations are involved. Strong consideration should also be given to "pseudodominant" inheritance of DFNB1. Pseudodominant inheritance refers to occurrence of an autosomal recessive disorder in two or more generations of a family and tends to occur when the carrier rate in the general population is high, as can be seen with assortative mating in the Deaf community.

Inner-ear defects (enlarged/dilated vestibular aqueduct and Mondini dysplasia) are associated with mutations in both SLC26A4 and POU3F4, and the detection of these temporal bone anomalies by computed tomography examination should prompt consideration of molecular genetic testing. ${ }^{74}$

Other genes known to cause nonsyndromic deafness are listed in Tables 3 to 7 . Although molecular genetic testing is available for a number of these genes, the large size of many of these genes and their relatively small contribution to deafness make it impractical to offer such testing on a clinical basis at this time.

\section{Prenatal testing}

Prenatal diagnosis for some forms of hereditary hearing loss is technically possible by analysis of DNA extracted from fetal cells. Fetal material can be obtained by amniocentesis at 15 to 18 weeks' gestation or chorionic villus sampling at 10 to 12 weeks' gestation. Gestational age is expressed as menstrual weeks calculated either from the first day of the last normal menstrual period or by ultrasound measurements. It is important to note that for optimal evaluation, the deafness-causing allele(s) of a deaf family member should be identified before prenatal testing is performed.

Requests for prenatal testing for conditions such as hearing loss are not common. Differences in perspective may exist among medical professionals and within families regarding the use of prenatal testing, particularly if the testing is being considered for the purpose of pregnancy termination rather than early diagnosis. Although most centers would consider decisions about prenatal testing to be the choice of the parents, careful discussion of these issues is appropriate. Preimplantation genetic diagnosis may be available for families in whom the deafness-causing mutation(s) has/have been identified in a deaf family member. 


\section{Related genetic counseling issues}

Communication with individuals who are deaf requires the services of a skilled interpreter. Many deaf people are interested in obtaining information about the cause of their own deafness, including information on medical, educational, and social services rather than information about prevention, reproduction, or family planning. As in all genetic counseling, it is important for the counselor to identify, acknowledge, and respect the individual's/family's questions, concerns, and fears. ${ }^{75,76}$ Furthermore, members of the Deaf community may view hearing loss as a distinguishing characteristic and not as a handicap, impairment, or medical condition requiring a "treatment" or "cure," or to be "prevented." In fact, having a child with deafness may be preferred by Deaf parents over having a child with normal hearing. ${ }^{77}$ The use of certain terms is preferred: probability or chance versus risk; deaf and hard of hearing versus hearing impaired. Terms such as "affected," "abnormal," and "disease-causing" should be avoided.

\section{Management}

Management of hereditary hearing loss is performed by a team that includes an otolaryngologist with expertise in the management of early childhood otologic disorders, an audiologist experienced in the assessment of hearing loss in children, a clinical geneticist, and a pediatrician. It may also be necessary to incorporate the expertise of an educator of the Deaf, a neurologist, and a pediatric ophthalmologist. Sequential audiologic examinations are essential to document the stability or progression of the hearing loss and to identify and treat superimposed hearing losses, such as middle ear effusion.

If an individual or the parents of a child raise concern about the possibility of hearing loss or, if the child is young, and there is concern regarding delayed speech development or poor social interaction, the initial evaluation should include a detailed history to explore possible acquired forms of hearing loss. A family history with pedigree construction, and a thorough otolaryngologic examination with particular attention to otoscopy and physical examination focusing on features that might suggest a syndromic type of deafness should also be performed.

An accurate test to quantify hearing acuity is paramount, and if one is not obtained, a return appointment should be scheduled as soon as possible to complete this part of the evaluation. On the basis of the data recorded from the initial evaluation, more specific tests can be requested that may include mutation screening of genes implicated in deafness.

In contrast with many other medical conditions, the management and treatment of hearing loss largely involves the social welfare system and incurs a growing cost to society. For a child with prelingual severe to profound sensorineural hearing loss, the total lifetime cost of hearing loss includes special education services, medical expenses, and the purchase of assisted devices, altogether exceeding U.S. $\$ 1,000,000 .{ }^{78}$ Thus, early screening is only the first step in a successful and costeffective program whose main goals are early diagnosis and management, language development, and long-term success after intervention.

\section{Intervention}

Auditory deprivation through the age of 2 years is associated with poor reading performance, poor communication skills, and poor speech production. Thus, an important component of the evaluation is to determine which avenue of habilitation best suits the individual. Interventional services should begin before the age of 6 months for all infants, and possible treatments include hearing aids, vibrotactile devices, or cochlear implantation, which are now considered in children aged more than 12 months with severe-toprofound hearing loss.

Although decreased cognitive skills and performance in mathematics and reading are associated with deafness, examination of persons with hereditary hearing loss has shown that these deficiencies are not intrinsically linked to the cause of the deafness. For example, assessment of cognitive skills in individuals with connexin 26-related deafness reveals a normal Hiskey intelligence quotient and normal reading performance after cochlear implantation. Yet, it must be noted that educational intervention alone is insufficient to completely remediate these deficiencies, and evidence suggests that early auditory intervention, whether through amplification, otologic surgery, or cochlear implantation, is effective. ${ }^{79}$

EHDI programs have reduced the average age at which hearing loss is confirmed (from 20-30 months to 2-3 months) and now provide screening for approximately $93 \%$ of all newborn infants before hospital discharge. ${ }^{80}$ Infants in whom appropriate intervention is begun within 6 months of life are able to maintain language, social, and emotional development that is commensurate with their physical development, in contrast with those in whom hearing loss is not detected until after 6 months of age. This observation is not dependent on the mode of communication, rather, improved language is found in early identified children who speak, sign, or use both modes of communication. ${ }^{81}$

Although EHDI programs have dramatically improved the average age at which hearing loss is first recognized, early newborn hearing screens may fail to identify children with progressive hearing loss, which accounts for approximately $15 \%$ of preschool children with sensorineural hearing loss. ${ }^{82}$ Furthermore, recent studies suggest that some children with GJB2 mutations may fail to express the phenotype of hearing loss at birth but then have a later onset of hearing loss. Whether this phenomena is attributable to the current EHDI criteria used to identify hearing loss or a true delay in the onset is unknown. ${ }^{83}$ Thus, it is essential for primary care providers to have a low threshold for reevaluating an infant's hearing if parents show concern about possible hearing loss or observe delays in speech development, even if their children have passed a newborn hearing screen.

\section{Agents and circumstances to avoid}

Noise exposure is a well-recognized environmental cause of hearing loss. Because this risk can be minimized by avoidance, persons with documented hearing loss should be counseled appropriately. 


\section{PREVENTION OF HEARING IMPAIRMENT}

An ideal therapy has not yet arrived to correct hearing loss through replacement or regeneration of inner and outer hair cells. Although practices to one day repair inner-ear damage are currently under way, existing measures for the prevention of hearing loss must attempt to decrease the frequency of acquired and genetic hearing loss. ${ }^{84-87}$ Improved implementation of vaccination programs in developing nations, avoidance of exacerbating factors such as noise, and focused genetic counseling and health education in populations with a high prevalence of consanguinity are several methods that may assist in decreasing the prevalence of acquired and hereditary hearing loss.

\section{RESOURCES}

- American Society for Deaf Children

3820 Hartzdale Drive

Camp Hill PA 17011

Phone: 800-942-2732 (parent hotline); 717-703-0073 (business V/TTY)

Fax: 717-909-5599

Email: asdc@deafchildren.org

www.deafchildren.org

- The Morton Hearing Research Group

www.brighamandwomens.org/bwh_hearing

- National Association of the Deaf

8630 Fenton Street Suite 820

Silver Spring MD 20910

Phone: 301-587-1788 (voice); 301-587-1789 (TTY)

Fax: 301-587-1791

Email: NADinfo@nad.org

www.nad.org

- National Library of Medicine Genetics Home Reference http://ghr.nlm.nih.gov/condition = nonsyndromicdeafness

- Alexander Graham Bell Association for the Deaf and Hard of Hearing

3417 Volta Place NW

Washington DC 20007

Phone: 866-337-5220; 202-337-5220; 202-337-5221 (TTY)

Fax: 202-337-8314

Email: info@agbell.org

www.agbell.org

- My Baby's Hearing

This site, developed with support from the National Institute on Deafness and Other Communication Disorders, provides information about newborn hearing screening and hearing loss.

www.babyhearing.org

\section{Suggested reading}

Holden-Pitt L, Albertorio J. Thirty years of the Annual Survey of Deaf and Hard-of-Hearing Children \& Youth: a glance over the decades. Am Ann Deaf 1998:143:72-76.

Kittrell AP, Arjmand EM. The age of diagnosis of sensorineural hearing impairment in children. Int J Pediatr Otorhinolaryngol 1997:40:97-106.
Meyerhoff WL, Cass S, Schwaber MK, Sculerati N, et al. Progressive sensorineural hearing loss in children. Otolaryngol Head Neck Surg 1994;110:569-579.

Reardon W. Genetic deafness. J Med Genet 1992;29:521526.

Rose SP. Genetic studies of profound prelingual deafness. PhD Thesis. Indianapolis: Indiana University, 1975.

Wander RJA, Jacobs C, Skjeldal OH. Refsum disease. In: Scriver CR, Beaudet AL, Sly WS, Valle D, editors. The metabolic and molecular basis of inherited disease. New York: McGraw Hill, 1995:3301-3321.

\section{ACKNOWLEDGMENTS}

This work was supported in part by National Institute of Health grants R01 DC02842 and R01 DC03544 (R. J. H. S.) and the Doris Duke Clinical Research Fellowship (A. K.).

\section{References}

1. Toriello HV, Reardon W, Gorlin RF, editors. Hereditary hearing loss and its syndromes, 2nd ed. New York: Oxford University Press, 2004.

2. Van Camp G, Smith RJH. Hereditary Hearing Loss Homepage, 2003. http:// webh01.ua.ac.be/hhh/. Accessed 24 January 2007.

3. Guide for the evaluation of hearing handicap. JAMA 1979;241:2055-2059.

4. Northern JL, Downs M. Hearing in children. Baltimore: Lippincott, Williams, and Wilkins, 2002.

5. Morton NE. Genetic epidemiology of hearing impairment. Ann N Y Acad Sci 1991; 630:16-31.

6. White KR. The current status of EHDI programs in the United States. Ment Retard Dev Disabil Res Rev 2003;9:79-88.

7. Marazita ML, Ploughman LM, Rawlings B, Remington E, et al. Genetic epidemiological studies of early-onset deafness in the U.S. school-age population. Am J Med Genet 1993;46:486-491.

8. Cohen MM, Gorlin RJ. Epidemiology, etiology, and genetic patterns. In: Gorlin RJ, Toriello HV, Cohen MM, editors. Hereditary hearing loss and its syndromes. New York: Oxford Press, 1995:9-21.

9. Green GE, Scott DA, McDonald JM, Woodworth GG, et al. Carrier rates in the midwestern United States for GJB2 mutations causing inherited deafness. JAMA 1999;281:2211-2216.

10. Fischel-Ghodsian N. Genetic factors in aminoglycoside toxicity. Ann N Y Acad Sci 1999;884:99-109.

11. Harris S, Ahlfors K, Ivarsson S, Lernmark B, et al. Congenital cytomegalovirus infection and sensorineural hearing loss. Ear Hear 1984;5:352-355.

12. Hicks T, Fowler K, Richardson M, Dahle A, et al. Congenital cytomegalovirus infection and neonatal auditory screening. J Pediatr 1993;123:779-782.

13. Schildroth AN. Congenital cytomegalovirus and deafness. Am J Audiol 1994;3:2738.

14. Ogawa H, Baba Y, Suzutani T, Inoue N, et al. Congenital cytomegalovirus infection diagnosed by polymerase chain reaction with the use of preserved umbilical cord in sensorineural hearing loss children. Laryngoscope 2006;116:1991-1994.

15. Gates G, Mills J. Presbycusis. Lancet 2005;366:1111-1120.

16. Guilford P, Ben Arab S, Blanchard S, Levilliers J, et al. Joint Committee on Infant Hearing; American Academy of Audiology; American Academy of Pediatrics; American Speech-Language-Hearing Association; Directors of Speech and Hearing Programs in State Health and Welfare Agencies. Year 2000 position statement: principles and guidelines for early hearing detection and intervention programs. J Pediatr 2000;106:798-817.

17. Baldwin CT, Hoth CF, Amos JA, da-Silva EO, et al. An exonic mutation in HuP2 paired domain gene causes Waardenburg's syndrome. Nature 1992;355:637-638.

18. Tassabehji M, Read AP, Newton VE, Harris R, et al. Waardenburg's syndrome patients have mutations in the human homologue of Pax-3 paired box gene. Nature 1992;355:635-636.

19. Hoth CF, Milunsky A, Lipsky N, Sheffer R, et al. Mutations in the paired domain of the human PAX3 gene cause Klein-Waardenburg syndrome (WS-III) as well as Waardenburg syndrome type I (WS-I). Am J Hum Genet 1993;52:455-462.

20. Tassabehji M, Newton VE, Read AP. Waardenburg syndrome type 2 caused by mutations in the human microphthalmia (MITF) gene. Nat Genet 1994;8:251-255. 
21. Sánchez-Martín M, Rodríguez-García A, Pérez-Losada J, Sagrera A, et al. SLUG (SNAI2) deletions in patients with Waardenburg disease. Hum Mol Genet 2002;11: 3231-3236.

22. Edery P, Attie T, Amiel J, Pelet A, et al. Mutation of the endothelin-3 gene in the Waardenburg-Hirschsprung phenotype (Shah-Waardenburg syndrome). Nat Genet 1996;12:442-444.

23. Hofstra RM, Osinga J, Tan-Sindhunata G, Wu Y, et al. A homozygous mutation in the endothelin-3 gene associated with a combines Waardenburg type 2 and Hirschsprung phenotype (Shah-Waardenburg syndrome). Nat Genet 1996;12:445-447.

24. Pingault V, Bondurand N, Kuhlbrodt K, Goerich DE, et al. SOX10 mutations in patients with Waardenburg-Hirschsprung disease. Nat Genet 1998;18:171-173.

25. Melnick M, Bixler D, Silk K, Yune H, et al. Autosomal dominant branchiootorenal dysplasia. Birth Defects Orig Artic Ser 1975;5:121-128.

26. Fraser FC, Ling D, Clogg D, Nogrady B. Genetic aspects of the BOR syndromebranchial fistulas, ear pits, hearing loss, and renal anomalies. Am J Med Genet 1978; 2:241-252.

27. Heimler A, Lieber E. Branchio-Oto-Renal syndrome: reduced penetrance and variable expressivity in four generations of a large kindred. Am J Med Genet 1986;25:1527.

28. Konig R, Fuchs S, Dukiet C. Branchio-oto-renal (BOR) syndrome: variable expressivity in a five-generation pedigree. Eur J Pediatr 1994;153:446-450.

29. Stratakis CA, Lin J-P, Rennert OM. Description of a large kindred with autosomal dominant inheritance of branchial arch anomalies, hearing loss and ear pits, and exclusion of the branchio-oto-renal (BOR) syndrome gene locus (chromosome 8q13.3). Am J Med Genet 1998;79:209-214.

30. Ruf RG, Xu PX, Silvius D, Otto EA, et al. SIX1 mutations cause Branchio-Oto-Renal syndrome by disruption of EYA1-SIX1-DNA complexes. Proc Natl Acad Sci U S A 2004;101:8090-8095.

31. Kalatzis V, Sahly I, El Amraoui A, Petit C. Eyal expression in the developing ear and kidney: towards the understanding of the pathogenesis of Branchio-Oto-Renal (BOR) syndrome. Dev Dyn 1998;213:486-499.

32. Xu PX, Zheng W, Huang L, Maire $\mathrm{P}$, et al. Six l is required for the early organogenesis of mammalian kidney. Development 2003;130:3085-3094.

33. Zheng W, Huang L, Wei ZB, Silvius D, et al. The role of Six 1 in mammalian auditory system development. Development 2003;130:3989-4000.

34. Williams CJ, Ganguly A, Considine E, McCarron S, et al. A-2àG transition at the 3' acceptor splice site of IVS17 characterizes the COL2A1 gene mutation in the original Stickler syndrome kindred. Am J Med Genet 1996;63:461-467.

35. Richards AJ, Yates JR, Williams R, Payne SJ, et al. A family with Stickler syndrome type 2 has a mutation in the COL11A1 gene resulting in the substitution of glycine 97 by valine in alpha 1 (XI) collagen. Hum Mol Genet 1996;5:1339-1343.

36. Vikkula M, Mariman EC, Lui VC, Zhidkova NI, et al. Autosomal dominant and recessive osteochondrodysplasias associated with the COL11A2 locus. Cell 1995;80: 431-437.

37. Wilkin DJ, Mortier GR, Johnson CL, Jones MC, et al. Correlation of linkage data with phenotype in eight families with Stickler syndrome. Am J Med Genet 1998;80: 121-127.

38. Yohay K. Neurofibromatosis types 1 and 2. Neurologist 2006;2:86-93.

39. National Institutes of Health Consensus Development Conference. Neurofibromatosis: conference statement. Arch Neurol 1988;45:475-478.

40. Phelps PD, Coffey RA, Trembath RC, Luxon LM, et al. Radiological malformations of the ear in Pendred syndrome. Clin Radiol 1998;53:268-273.

41. Reardon W, O'Mahoney CF, Trembath R, Jan H, et al. Enlarged vestibular aqueduct: a radiological marker of Pendred syndrome, and mutations of the PDS gene. QJM 2000;93:99-104.

42. Newton VE. Aetiology of bilateral sensori-neural hearing loss in young children. $J$ Laryngol Otol Suppl 1985;10:1-57.

43. Arnos KS, Cunningham M, Israel J, Marazita ML. Innovative approach to genetic counseling services for the deaf population. Am J Med Genet 1992;44:345-351.

44. Rosenberg T, Haim M, Hauch AM, Parving A. The prevalence of Usher syndrome and other retinal dystrophy-hearing impairment associations. Clin Genet 1997;51: 314-321.

45. Kimberling WJ, Moller CG, Davenport SL, Lund G, et al. Usher syndrome: clinical findings and gene localization studies. Laryngoscope 1989;99:66-72.

46. Neyroud N, Tesson F, Denjoy I, Leibovici M, et al. A novel mutation in the potassium channel gene KVLTQ1 causes Jervell Lange-Nielsen cardioauditory syndrome. Nat Genet 1997;15:186-189.

47. Schulze-Bahr E, Wang Q, Wedekind H, Haverkamp W, et al. KCNE1 mutation cause Jervell and Lange-Nielsen syndrome. Nat Genet 1997;17:267-268.

48. Wolf B, Spencer R, Gleason T. Hearing loss is a common feature of symptomatic children with profound biotinidase deficiency. J Pediatr 2002;140:242-246.

49. Heller AJ, Stanley C, Shaia WT, Sismanis A, et al. Localization of biotinidase in the brain: implications for its role in hearing loss in biotinidase deficiency. Hear Res 2002;173:62-68.
50. Wander RJA, Jacobs C, Skjeldal OH. Refsum disease. In: Scriver CR, Beaudet AL, Sly WS, Valle D, editors. The metabolic and molecular basis of inherited disease. New York: McGraw Hill, 1995:3301-3321.

51. van den Brink DM, Wanders RJ. Phytanic acid: production from phytol, its breakdown and role in human disease. Cell 2006;63:1752-1765.

52. Govan J. Ocular manifestations of Alport's syndrome: a hereditary disorder of basement membranes? Br J Ophthalmol 1983;67:493-503.

53. Barker DF, Hostikka SL, Zhou J, Chow LT, et al. Identification of mutations in the COL4A5 collagen gene in Alport syndrome. Science 1990;248:1224-1227.

54. Mohr J, Mageroy K. Sex-linked deafness of a possibly new type. Acta Genet Statist Med 1960;10:54-62.

55. Tranebjaerg L, Schwartz C, Eriksen H, Andreasson S, et al. A new X linked recessive deafness syndrome with blindness, dystonia, fractures, and mental deficiency is linked to Xq22. J Med Genet 1995;32:257-263.

56. Jin H, May M, Tranebjaerg L, Kendall E, et al. A novel X-linked gene, DDP, shows mutations in families with deafness (DFN-1), dystonia, mental deficiency and blindness. Nat Genet 1996;14:177-180.

57. Koehler CM, Leuenberger D, Merchant S, Renold A, et al. Human deafness dystonia syndrome is a mitochondrial disease. Proc Natl Acad Sci U S A 1999;96: 2141-2146.

58. Usami S, Abe S, Akita J, Namba A, et al. Prevalence of mitochondrial gene mutation among hearing impaired patients. J Med Genet 2000;37:38-40.

59. Majamaa K, Moilanen JS, Uimonen S, Remes AM, et al. Epidemiology of A3243G, the mutation for mitochondrial encephalomyopathy, lactic acidosis, and stroke-like episodes: prevalence of the mutation in an adult population. Am J Hum Genet 1998;63:447-454

60. Kadowaki T, Kadowaki H, Mori Y, Tobe K, et al. A subtype of diabetes mellitus associated with a mutation of mitochondrial DNA. N Engl J Med 1994;330:962968.

61. Cremers CW, Marres HA, van Rijn PM. Nonsyndromal profound genetic deafness in childhood. Ann N Y Acad Sci 1991;630:191-196.

62. Van Camp G, Willems PJ, Smith RJ. Nonsyndromic hearing impairment: unparalleled heterogeneity. Am J Hum Genet 1997;60:758-764.

63. Zelante L, Gasparini P, Estivill X, Melchionda S, et al. Connexin26 mutation associated with the most common form of non- syndromic neurosensory autosomal recessive deafness (DFNB1) in Mediterraneans. Hum Mol Genet 1997;6: 1605-1609.

64. Estivill X, Fortina P, Surrey S, Rabionet R, et al. Connexin-26 mutations in sporadic and inherited sensorineural deafness. Lancet 1998;351:394-398.

65. Kelley PM, Harris DJ, Comer BC, Askew JW, et al. Novel mutations in the connexin 26 gene (GJB2) that cause autosomal recessive (DFNB1) hearing loss. Am J Hum Genet 1998;62:792-799.

66. Scott DA, Kraft ML, Carmi R, Ramesh A, et al. Identification of mutations in the connexin 26 gene that cause autosomal recessive nonsyndromic hearing loss. Hum Mutat 1988;11:387-394.

67. Zbar RI, Ramesh A, Srisailapathy CR, Fukushima K, et al. Passage to India: the search for genes causing autosomal recessive nonsyndromic hearing loss. Otolaryngol Head Neck Surg 1998;118:333-337.

68. Snoeckx RL, Huygen PL, Feldmann D, Marlin S, et al. GJB2 mutations and degree of hearing loss: a multicenter study. Am J Hum Genet 2005;77:945-957.

69. Vore AP, Chang EH, Hoppe JE, Butler MG, et al. Deletion of and novel missense mutation in POU3F4 in 2 families segregating X-linked nonsyndromic deafness. Arch Otolaryngol Head Neck Surg 2005;131:1057-1063.

70. Fischel-Ghodsian N. Mitochondrial mutations and hearing loss: paradigm for mitochondrial genetics. Am J Hum Genet 1998;62:15-19.

71. Hone SW, Smith RJ. Medical evaluation of pediatric hearing loss: laboratory, radiographic, and genetic testing. Otolaryngol Clin North Am 2002;35:751-764.

72. Zalzal GH, Shott SR, Towbin R, Cotton RT. Value of CT scan in the diagnosis of temporal bone diseases in children. Laryngoscope 1986;96:27-32.

73. Bamiou D, Phelps P, Sirimanna T. Temporal bone computed tomography findings in bilateral sensorineural hearing loss. Int J Pediatr Otorhinolaryngol 1999;51:91-99.

74. Vore AP, Chang EH, Hoppe JE, Butler MG, et al. Deletion of and novel missense mutation in POU3F4 in 2 families segregating X-linked nonsyndromic deafness. Arch Otolaryngol Head Neck Surg 2005;131:1057-1063.

75. Middleton A, Hewison J, Mueller RF. Attitudes of deaf adults toward genetic testing for hereditary deafness. Am J Hum Genet 1998;63:1175-1180.

76. Arnos KS. The implications of genetic testing for deafness. Ear Hear 2003;24:324331.

77. Arnos KS, Israel J, Cunningham M. Genetic counseling of the deaf-medical and cultural considerations. Ann N Y Acad Sci 1992;630:212-222.

78. Mohr P, Feldman JJ, Dunbar JL. The societal costs of severe to profound hearing los in the United States. Int J Technol Assess Health Care 2000;16:1120-1135.

79. Downs MP, Yoshinaga-Itano C. The efficacy of early identification and intervention for children with hearing impairment. Pediatr Clin North Am 1999;46:79-87. 


\section{Kochhar et al.}

80. White KR. National Center for Hearing Assessment and Management website, 2006. http://www.infanthearing.org. Accessed 10 February 2007.

81. Yoshinaga-Itano C, Seday A, Coulter DK, Mehl AL. Langauge of early- and lateridentified children with hearing loss. J Pediatr 1998;102:1161-1171.

82. Hone SW, Smith RJ. Medical evaluation of pediatric hearing loss: laboratory, radiographic, and genetic testing. Otolaryngol Clin North Am ;200235:751-764.

83. Norris VW, Arnos KS, Hanks WD, Xia X, et al. Does universal newborn hearing screening identify all children with GJB2 (connexin 26) deafness? Penetrance of GJB2 deafness. Ear Hear 2006;27:732-741.
84. Minoda R, Izumikawa M, Kawamoto K, Raphael Y. Strategies for replacing lost cochlear hair cells. Neuroreport 2004;15:1089-1092.

85. Shou J, Zheng JL, Gao WQ. Robust generation of new hair cells in mature mammalian inner ear by adenoviral expression of Hath1. Mol Cell Neurosci 2003;23:169_ 179.

86. Kawamoto K, Ishimoto S, Minoda R, Brough DE, et al. Mathl gene transfer generates new cochlear hair cells in mature guinea pigs in vivo. J Neurosci 2003;23:4395-4400.

87. Smith R, Bale J, White K. Sensorineural hearing loss in children. Lancet 2005;365: 879-890. 